\title{
NARRATIVA, TRADIÇÃO E EXPERIÊNCIA: ANÁLISE DE ASPECTOS DA LITERATURA TRADICIONAL/ORAL/POPULAR EM $A$ VIAGEM DO ELEFANTE, DE JOSÉ SARAMAGO
}

\begin{abstract}
Max Alexandre de Paula Gonçalves ${ }^{1}$
RESUMO: Este artigo possui o objetivo de analisar aspectos da literatura tradicional/oral/popular existentes no livro A viagem do elefante, de José Saramago. Pretende-se investigar a representação de elementos da literatura tradicional e oral na cultura escrita à luz das teorias de Walter Benjamin sobre o narrador e a narrativa, presentes nos ensaios "O narrador. Considerações sobre a obra de Nikolai Leskov" e "Experiência e pobreza". Ao ressignificar provérbios e metáforas - gêneros da literatura tradicional/oral/popular -, Saramago consegue transmitir saber e experiência na narrativa sobre a viagem do elefante Salomão. Além disso, é importante observar que essa sabedoria é emitida pela voz de personagens ex-cêntricas da História, tais como o cornaca indiano Subhro.
\end{abstract}

PALAVRAS-CHAVE: Literatura Oral - Narrativa - José Saramago - Cultura Escrita - Memória

RESUMÉ: Cet article a l'objectif d'analyser des aspects de la littérature tradittionelle/orale/populaire existants dans le livre Le voyage de l'éléphant, de José Saramago. Par le débat de cet oeuvre à la lumière des théories de Walter Benjamin sur le narrateur et la narrative, présents dans les essais Le narrateur. Réfléxions à propos de l'oeuvre de Nicolas Leskov et Expérience et pauvreté, nous avons l'intention de rechercher sur la représentation des éléments de la littérature tradittionelle et orale dans la culture écrite. Quand Saramago ressignifie les proverbes et les métaphores - genres de la littérature tradicionelle/orale/populaire -, l'auteur réussit transmettre du savoir et de l'expérience dans la narrative sur l'éléphant Salomão. En plus, il est important d'observer que cette sagesse est émise par la voix des personnages ex-centriques de l'Histoire, tels que le cornac indien Subhro.

MOTS-CLÉS: Littérature Orale - Narrative - José Saramago - Culture Écrite Mémoire

Que José Saramago foi um grande escritor, isso é fato, seus livros Memorial do convento (1982), O ano da morte de Ricardo Reis (1984), História do cerco de Lisboa (1989) e Ensaio sobre a cegueira (1995) são reconhecidos mundialmente como obrasprimas, justificando o prêmio Nobel de Literatura concedido ao escritor português em 1998. Aliás, Ensaio sobre a cegueira, recentemente, chegou a ser adaptado para uma versão cinematográfica homônima. Contudo, agora em 2010, a Literatura perdeu

\footnotetext{
${ }^{1}$ Aluno regular de mestrado pelo Programa de Pós-Graduação em Letras - Estudos Literários da Universidade Estadual de Londrina. E-mail: max_alehis@hotmail.com
} 
definitivamente de seus domínios José Saramago. No entanto, essa perda já se mostrara possível anteriormente, pois devido a uma doença respiratória, seu penúltimo livro, $A$ viagem do elefante (2008), quase não foi concluído. Mesmo assim, com um intervalo de meses, Saramago terminou essa história, e à análise dela que nos prestaremos nesse trabalho.

Já são marcas da obra de Saramago o humor e a ironia para mostrar a habitualmente difícil relação do homem consigo mesmo. Então, acrescente-se a isso a relação do homem com os animais, ou melhor, com um animal, mais especificamente um elefante, de nome Salomão. É este o enredo da trama sobre a viagem do elefante Salomão, que partiu de Portugal no século XVI em direção a Viena, na Áustria, como presente de Dom João III, rei português, e de sua esposa Catarina d'Áustria ao arquiduque austríaco Maximiliano II, genro do imperador Carlos V. É essa a história em que se basearão as nossas posteriores reflexões.

Abordaremos, entre algumas das questões, qual a proximidade dessa narrativa de Saramago com as histórias orais da cultura popular; observaremos como aparece a representação da oralidade numa cultura escrita, quer dizer, a ficcionalização de elementos orais materializados no livro. Como funciona esse procedimento? Aliás, como fica essa passagem da literatura tradicional e oral para a literatura escrita? A transmissão e a tradição sofrem desvios, ou ainda, perdas? São alguns dos nossos questionamentos. Nosso arcabouço teórico contará com as teorias de Walter Benjamin sobre a narrativa. Além disso, utilizaremos também apontamentos de outros pesquisadores que podem contribuir para o desenvolvimento de nossas problemáticas.

Iniciaremos o nosso trabalho pela teoria benjaminiana sobre a narrativa e a elucidaremos concomitantemente com o texto de Saramago.

Há um ensaio de Walter Benjamin intitulado O narrador. Considerações sobre a obra de Nikolai Leskov, de 1936, em que o crítico alemão escreve que a arte de narrar estaria em vias de extinção, pois o narrador já seria algo de distante naquele momento. Então, Benjamin anuncia Leskov como um dos últimos narradores da atualidade. Contemporâneo de Dostoievski e de Tolstoi, foi a partir de Leskov que Benjamin elaborou suas reflexões, aliás, ele considerou que localizar um narrador à sua época exigia uma distância apropriada e um ângulo favorável de observação. Segundo o crítico alemão, a dificuldade em narrar ocorre porque na atualidade estamos privados de 
uma faculdade que em outros tempos nos "parecia segura e inalienável: a faculdade de intercambiar experiências" (BENJAMIN, 1994, p. 198). Esse ponto é importante, pois em Experiência e pobreza, um texto anterior ao do ensaio sobre Leskov, Benjamin já expusera que o ato de narrar uma história estaria ligado à função de transmitir uma experiência, e esta, por sua vez, possuiria um significado muito peculiar:

[A experiência] sempre fora comunicada aos mais jovens. De forma concisa, com a autoridade da velhice, em provérbios; de forma prolixa, com a sua loquacidade, em histórias; muitas vezes como narrativas de países longínquos, diante da lareira, contadas a pais e netos (BENJAMIN, 1994, p. 114).

No entanto, recorrer à experiência é uma atitude em baixa para Benjamin "Quem tentará, sequer, lidar com a juventude invocando a sua experiência?" (BENJAMIN, 1994, p. 114). Não devemos esquecer que Benjamin escreveu os dois ensaios que citamos após uma das piores experiências da história: a $1^{\mathrm{a}}$ Guerra Mundial. Esse evento marca uma nova relação das pessoas com a experiência, pois Benjamin percebeu que os combatentes voltavam silenciosos do campo de batalha, ou seja, retornavam mais pobres em experiência comunicável. Conforme o teórico, isso ocorria por conta das experiências que as gerações entre 1914 e 1918 tiveram, uma vez que elas foram radicalmente desmoralizadas: "experiência pela guerra de trincheiras, a experiência econômica pela inflação, a experiência do corpo pela fome, a experiência moral pelos governantes" (BENJAMIN, 1994, p. 114). Aqui se encontraria o problema nas narrativas contemporâneas: a ausência de experiências transmissíveis, pois, voltando ao texto sobre o narrador, Benjamin comenta que a experiência que "passa de pessoa a pessoa é a fonte a que recorreram todos os narradores. E entre as narrativas escritas, as melhores são as que menos se distinguem das histórias orais contadas pelos inúmeros narradores anônimos" (BENJAMIN, p. 198). Percebe-se assim o enaltecimento das narrativas orais por Benjamin, pois ele as compreende como as melhores formas de transmissão da experiência, ou ainda, da tradição. Podemos adiantar que $A$ viagem do elefante se encaixa nessa consideração de Benjamin, pois esse conto oriundo da narrativa oral, ao ser passado para a escrita, consegue preservar a tarefa atribuída à narrativa, ou seja, a de comunicar uma experiência, por meio de recursos que abordaremos logo mais. 
Um segundo aspecto da narrativa, na maneira como Benjamin a compreende, é a da narrativa ter "sempre em si, às vezes de forma latente, uma dimensão utilitária" (Ibid., p. 200). Essa utilidade pode aparecer por diversas formas: num ensinamento moral, numa sugestão prática, num provérbio ou numa norma de vida - de qualquer modo, o narrador tem por característica fornecer conselhos sábios. Vamos nos deter agora numa dessas formas, o provérbio.

O provérbio é uma característica das obras de Saramago, desde Levantado do Chão (1980) ao Ensaio sobre a lucidez (2004) (Cf. DUARTE, 2009). Em Memória da literatura oral. A dinâmica discursiva da literatura oral: reflexões sobre a noção de etnotexto, Jean-Noël Pelen concebe o provérbio como um gênero da literatura oral, pois ele enuncia e confirma a ordem estabelecida de determinada comunidade, da qual pertence e é o reflexo. Dessa forma, Pelen define o provérbio da seguinte forma:

O provérbio é caracterizado pela rapidez de sua expressão e a arte do locutor está em saber empregá-lo com sabedoria e oportunamente. (...) ele está mais frequentemente inserido dentro de uma palavra compartilhada, dentro de uma conversação, que ele vem marcar com sua densidade informativa (PELEN, 2001, p. 54).

Se anteriormente vimos que Walter Benjamin considera que as melhores histórias escritas são as que se aproximam das narrativas orais, então, o provérbio, enquanto gênero de literatura oral, ao aparecer ocasionalmente seja na voz do narrador ou na dos personagens da história, torna o conto de Saramago muito mais próximo da literatura tradicional/oral/popular, o que o aproxima mais da idéia benjaminiana sobre a narrativa.

Em um texto muito interessante, Helena Margarida Vaz Duarte observou o jogo intertextual que os romances de José Saramago fazem com os textos da literatura tradicional/oral/popular. A crítica propôs que o provérbio é apropriado e recriado ao adquirir um estatuto literário pelas mãos do literato português. Além disso, o uso intertextual desses textos representa uma tentativa de transgredir as "verdades" da História e da Literatura, isto é, a busca por um passado reconstruído a partir de vozes até então silenciosas ou silenciadas. É a vez das personagens "ex-cêntricas" - as excluídas pela História oficial - com o saber que emana delas, que ganham voz no olhar de Saramago. É essa atitude que permite o cornaca Subhro, de A viagem do elefante, participar ativamente de um episódio envolvendo duas das coroas mais importantes da 
Europa do século XVI. Assim, os provérbios são utilizados por Saramago na sua forma fixada, porém ele “inova estes enunciados aparentemente cristalizados ao alterá-los, parodiá-los, amplificando-os, cruzando-os com textos eruditos, num processo de constante (re)criação, num processo dinâmico entre tradição e inovação" (DUARTE, 2009, p. 120).

Duarte tem por mérito, ainda, o trabalho de ter registrado o número de ocorrências proverbiais nos onze romances de Saramago que analisou, entre eles, Memorial do convento e A jangada de pedra. Todavia, preferimos seguir o outro caminho tomado pela autora: verificar que os ditados populares contribuem para o diálogo intertextual, que eles possuem "uma função de dessacralização de verdades instituídas na caracterização de certas personagens e colaboram na explicação e na condensação das situações narradas, como 'narrativas mínimas' que são" (DUARTE, 2009, p. 121). Apontaremos alguns casos de ocorrência proverbial encontrados em $A$ viagem do elefante, isto será importante para elucidar a dimensão utilitária do provérbio nessa narrativa, o qual é definido também por conter juízos de valor ou morais sempre implícitos.

O primeiro provérbio que identificamos em $A$ viagem do elefante ocorre quando o secretário Pêro de Alcáçova Carneiro fica na dúvida se elogia ou não o rei por causa da escolha de um estribeiro-mor, que sua alteza havia feito para levar a carta oferecendo o elefante como presente ao arquiduque da Áustria. Eis que a lembrança do pai surge com um provérbio pertinente à situação: "Cuidado, meu filho, uma adulação repetida acabará inevitavelmente por tornar-se insatisfatória, e portanto ferirá como uma ofensa" (SARAMAGO, 2008, p. 16). É interessante notar que esse primeiro provérbio apareça justamente como um conselho, quer dizer, uma opinião que transmite a experiência de um homem mais velho, Antonio Carneiro, pai do secretário, pessoa que exercera o mesmo cargo antes do filho, e que, possivelmente já havia estado na mesma condição.

Há ainda um provérbio justificando como são relativos os juízos de valores. Novamente, os personagens do rei e do secretário estão envolvidos. Quando Dom João III vê o elefante pergunta ao secretário o que ele acha do animal, eis que prontamente este responde: "Bonito ou feio, meu senhor, são meras expressões relativas, para a coruja até os seus corujinhos são bonitos" (Ibid., p 22). Podemos comparar este 
provérbio que explicita o relativismo que cerca as compreensões da realidade com um provérbio que aparece em A jangada de pedra, registrado por Helena Margarida Vaz Duarte: "cada um de nós vê o mundo com os olhos que tem" (SARAMAGO apud DUARTE, 2009, p. 128).

Utilizando novamente o trabalho de Duarte, prosseguimos com outro provérbio que a autora havia encontrado somente em História do cerco de Lisboa: "no melhor pano pode cair a nódoa”. Em muitos casos como esse, o provérbio é empregado a fim de condensar uma narrativa mínima, que nos romances de Saramago, representa "a estória da história que está a ser contada" (DUARTE, 2009, p. 125). Por exemplo, o uso de "no melhor pano pode cair a nódoa" representa a breve história de Subhro, o cornaca, e Salomão, o elefante, da chegada a Belém até a saída para Valladolid.

Quando foram para ali lançados, a curiosidade popular subiu ao rubro e a própria corte chegou a organizar selectas excursões a belém de fidalgos e fidalgas, de damas e cavalheiros para verem o paquiderme, mas em pouco tempo o interesse começou a decair, e o resultado viu$\mathrm{se}$, as roupas indianas do cornaca transformaram-se em farrapos e os pêlos e as pintas do elefante quase vieram a desaparecer sob a crosta de sujidade acumulada durante dois anos. Não é, porém, a situação de agora (SARAMAGO, 2008, pp. 33-34).

Vemos então que o provérbio aqui significa as mudanças pelas quais passaram Subhro e Salomão, os quais, em um primeiro momento, ocuparam um papel importante no imaginário da corte portuguesa, e, depois, foram esquecidos até que novamente recuperassem seu prestígio pela razão do elefante ter se tornado um presente para o arquiduque Maximiliano II. Assim, nas poucas palavras que o provérbio emprega, temos uma pequena história de auge, declínio e ascensão. Como diz o próprio Subhro: "assim é a vida, triunfo e olvido".

Todavia, o provérbio "No melhor pano cai a nódoa" ao significar que mesmo o melhor pode sofrer algo de pior, é evocado novamente pelo narrador quando comenta a atitude do arquiduque Maximiliano II de fechar a caravana com couraceiros - uma força militar - para evitar ataques.

É certo que não estamos na calábria ou na sícilia, mas sim nas civilizadas terras da ligúria, às quais se hão-se seguir a lombardia e o veneto, mas, como no melhor pano cai a nódoa, como tantas vezes a sabedoria popular tem avisado, bem faz o arquiduque em manter a sua retaguarda protegida. Resta saber o que lhe virá do alto céu. (SARAMAGO, 2008, p. 179) 
Mais um provérbio que surge evocando a experiência e saber que este enunciado carrega aparece nas palavras do cura, que o utiliza para responder as gentes que lêem os evangelhos para contestar os ensinamentos do padre: "quem se mete por atalhos, nunca sai de sobressaltos" (SARAMAGO, 2008, p. 80). É interessante destacar nessa passagem que o padre nos dá indícios da relevância da cultura oral para a transmissão de um saber, pois, o aldeão, ao tentar contestar o cura pela leitura que realizou do evangelho, é repreendido pelo religioso, recebendo a indicação que ele deveria prestar mais atenção na missa. Além disso, esse trecho também demonstra um predomínio da voz oficial sobre a voz não-oficial, já que quem lia o evangelho para o aldeão era a filha dele, missão que o padre assume para si como exclusiva.

Mas a comunicação da sabedoria popular não possui como único veículo o provérbio. Há outras formas de enunciados, e Saramago também se apossa delas. Uma dessas categorias é a metáfora. Há uma muito bela que extraímos de $A$ viagem do elefante, citada pelo narrador da história, quando a rainha de Portugal, Catarina de Áustria, é questionada pelo narrador se lembrará do elefante Salomão depois de dois ou três anos.

\footnotetext{
O passado é um imenso pedregal que muitos gostariam de percorrer como se de uma auto-estrada se tratasse, enquanto outros, pacientemente, vão de pedra em pedra. E as levantam, porque precisam de saber o que há por baixo delas. Às vezes saem-lhes lacraus ou escolopendras, grossas roscas brancas ou crisálidas a ponto, mas não é impossível que, ao menos uma vez, apareça um elefante, e que esse elefante traga sobre os ombros um cornaca chamado subhro, nome que significa branco (...) (SARAMAGO, 2008, p. 33).
}

$\mathrm{Na}$ maioria das vezes, como bem verificou Duarte, as múltiplas ocorrências proverbiais e metafóricas não são enunciadas pelas personagens ditas populares, cabendo este papel ao narrador, "mas também a personagens canonicamente consideradas superiores, sejam aquelas que detêm o poder (...), sejam as personagens históricas D. João V e D. Afonso Henriques, o heterônimo Ricardo Reis e também Deus" (DUARTE, 2009, p.122), No nosso caso, isso também é válido, com o rei D. João III ou o arquiduque Maximiliano II produzindo o enunciado. Dessa forma, a linguagem parêmica atua como um recurso para "humanizar" as personagens canonicamente destacadas e elevar as anônimas, numa tentativa de "dessacralização da 
verdade que a História, a Literatura e os Evangelhos instituíram” (DUARTE, 2009, p. 122).

O caráter utilitário do provérbio, na forma de um conselho ou de uma sugestão, quando tecido na substância viva da existência adquire um nome: sabedoria, de acordo com Benjamin. Então, Saramago, ao mesmo tempo em que salva a narrativa de sua morte recupera a sabedoria ao colocá-la na voz de personagens de quem não esperaríamos que ela emergisse.

Por que insistimos nessa discussão sobre a dimensão utilitária da narrativa por meio de enunciados, tais como o provérbio ou a metáfora? Pois, Benjamin compreende que o surgimento do romance no período moderno seria o primeiro sinal da evolução que culminaria na morte da narrativa. E Saramago, apesar de fugir das terminologias, prefere chamar essa história sobre a viagem de Salomão de "conto" e não romance, pela falta de ingredientes que caracterizam um. Ao avaliarmos tudo o que dissemos até aqui sobre a cultura oral/popular/tradicional na narrativa de Saramago, podemos responder pela própria teoria de Benjamin, que prevê o romance como estando vinculado essencialmente a uma cultura escrita, visto que a sua difusão só foi possível com a invenção da imprensa - da qual o folhetim faz parte. Entretanto, todas as outras formas de prosa - contos de fada, lendas e mesmo novelas - são oriundas da tradição oral, e continuam a alimentar a mesma. Isso estaria relacionado ao fato de que "o narrador retira da experiência o que ele conta: sua própria experiência ou a relatada pelos ouvintes. E incorpora as coisas narradas à experiência dos seus ouvintes" (BENJAMIN, 1994, p. 201). Já o romance é diferente das outras formas de prosa que apontamos aqui, pois se origina no indivíduo isolado, que não dá conselhos, mas que também não os recebe. O romance não possui a dimensão utilitária de comunicar sabedoria, pois se mostra totalmente refratário ao conselho e ausente de sabedoria ${ }^{1}$.

De forma um tanto profética, Benjamin ainda nos deixa pistas para compreender o conto e o narrador de José Saramago. Uma delas diz que a narrativa deve ser concisa para que a memória a retenha, já que o ouvinte tenderá a contá-la e recontá-la um dia se conseguir assimilá-la, quer dizer, o ouvinte pode vir-a-ser um narrador e, mais interessante ainda, ele pode imprimir a sua marca na narrativa, "como a mão do oleiro na argila do vaso" (BENJAMIN, 1994, p. 205).

\footnotetext{
${ }^{1}$ Essa proposição segue as idéias de Walter Benjamin no ensaio "O narrador. Considerações sobre a obra de Nikolai Leskov". Os argumentamos da nossa discussão se restringem ao conto $A$ viagem do elefante.
} 
Além disso, diz Benjamin na seqüência, "os narradores gostam de começar sua história com uma descrição das circunstâncias em que foram informados dos fatos que vão contar a seguir, a menos que prefiram atribuir essa história a uma experiência autobiográfica" (BENJAMIN, 1994, p. 205). Ora, e não vemos essa característica em Saramago quando ele escreve antes do início da história como descobriu sobre a viagem do elefante? Ou seja, estamos querendo apontar que, em $A$ viagem do elefante, autor e narrador não estão separados e tudo indica que o próprio Saramago seria o narrador dessa história.

Se Gilda Lopes Encarnação não fosse leitora de português na Universidade Salzburgo, se eu não tivesse sido convidado para ir falar aos alunos, se Gilda não me tivesse convidado para jantar no restaurante $O$ Elefante, este livro não existiria. Foi preciso que os ignotos fados se conjugassem na cidade de Mozart para que eu pudesse ter perguntado: 'Que figuras são aquelas?'As figuras eram umas pequenas esculturas de madeira postas em fila, a primeira das quais, olhando da direita para a esquerda, era a nossa Torre de Belém. Vinham a seguir representações de vários edifícios e monumentos europeus que manifestamente enunciavam um itinerário. Foi me dito que se tratava da viagem de um elefante que, no século XVI, exactamente em 1551, sendo rei D. João III, foi levado de Lisboa a Viena (SARAMAGO, 2008, p. 5).

Pelos comentários que o narrador faz em determinados momentos da trama, podemos vê-lo como contemporâneo. Vejamos no seguinte trecho a sua atualidade quando ele se presta a fazer comentários sobre as medidas de tempo utilizadas pelos personagens do século XVI:

(...) enquanto o cornaca e os que o acompanham, porque não teriam outra maneira de entender-se, irão continuar a falar de distâncias de acordo com os usos e costumes do seu tempo, nós, para que possamos perceber o que ali se vai passando nesta matéria, usaremos as nossas modernas medidas itinerárias, sem ter de recorrer constantemente a fastidiosas tábuas de conversão. No fundo, será, como se num filme, desconhecido naquele século dezasseis, estivéssemos a colar legendas na nossa língua para suprir a ignorância ou um insuficiente conhecimento da língua falada pelos actores (SARAMAGO, 2008, p. $38)$.

Possui ainda $A$ viagem do elefante outro pressuposto da teoria de Benjamin sobre a narrativa e o narrador, qual seja, a de que a história contada pelo narrador deve estar inserida na história natural, quer dizer, uma história que lide com a idéia de nascimento e morte, ou ainda de começo e fim, do homem ou dos eventos históricos. 
Ora, geralmente as histórias de Saramago estão inseridas dentro da história natural e com $A$ viagem do elefante não é diferente. Por exemplo, há a referência a Inquisição e o medo dela por parte das pessoas, citada tanto pelo narrador como pelas personagens, como podemos ler no seguinte diálogo entre o rei Dom João III e o seu secretário:

\begin{abstract}
Não sei, meu senhor, se este será o melhor tempo de ir para o céu, Que quer isso dizer, Vem aí a inquisição, meu senhor, acabaram-se os salvos-condutos de confissão e absolvição, A inquisição manterá a unidade entre os cristãos, esse é o seu objectivo, Santo objectivo, sem dúvida, meu senhor, resta saber por que meios o alcançará, Se o objectivo é santo, santos serão também os meios de que se servir (...) (SARAMAGO, 2008 p. 17).
\end{abstract}

Ainda mais, vemos também alusões aos acontecimentos da Reforma protestante e da posição de simpatia de Maximiliano II pelas novas idéias de Lutero, além de como os eventos religiosos e políticos da história natural se relacionam com a história narrada. Observemos como o padre explica para Subhro o porquê da necessidade do "milagre" de o elefante se ajoelhar em frente da basílica de Santo Antonio:

Porque Lutero, apesar de morto, anda a causar grande prejuízo à nossa santa religião, tudo quanto possa ajudar-nos a reduzir os efeitos da predicação protestante será bem-vindo, recorda que ainda só há pouco mais de trinta anos foram afixadas as suas nefandas teses às portas da igreja do castelo de wittenberg e o protestantismo vai alastrando como uma inundação por toda a europa, Não sei nada dessas teses, ou lá o que seja, Nem precisas de saber, basta que tenhas fé (...) (SARAMAGO, 2008, pp. 189-190).

Além disso, o narrador para Benjamin encarna uma forma épica em que todas as histórias se articulam, uma história na outra, como numa espécie de rede. Esse narrador se assemelha a Scherazade, que imagina uma história dentro da outra nas narrativas de Mil e uma noites. Não seria esse o caso de Subhro ao contar a origem do deus hindu Ganeixa? Ou quando dentro dessa história o personagem articula a cosmogonia na percepção da religião hindu?

Gostaríamos de finalizar esse artigo aplicando os argumentos de Henriqueta Maria Gonçalves, expostos no seu texto Encontros e desencontros da literatura tradicional/oral na literatura escrita.

Para essa pesquisadora, escritor e mundo estão relacionados, de maneira que, respectivamente, o primeiro não se encontra isolado. Vozes estão a todo o momento pululando na cabeça do escritor, e a sua escrita demonstra essa suposição. Não se pode 
acreditar ingenuamente que o universo de escrita do literato seja constituído sem a presença dessas vozes. Ao seguir este raciocínio, abrimos portas para compreender que A viagem do elefante é uma re-escrita em que foi acrescentado algo. Não esqueçamos como ocorre a idéia de escrever o conto, comentada acima. Assim, de acordo com Gonçalves, podemos entender que essa obra de José Saramago é um objeto estético "refeito no conflito das vozes interiores oferecido como objeto original, resultante de uma visão particular do mundo e que se configura como autêntico e pessoal, a marcar uma presença, uma sensibilidade individual no seio da Literatura" (GONÇALVES, 2009, p. 155).

Portanto, a retomada de um texto proveniente da tradição oral, como é o caso do nosso objeto de estudo, demonstra uma preocupação reprodutora das vozes que o veem indo em direção ao abismo do esquecimento. Por isso, as narrativas de Saramago são preenchidas com provérbios, expressões idiomáticas e metáforas, pois é assim que ele expressa essas vozes antigas. Contudo, a atitude de registro e cautela dessas vozes por parte do autor não deve ser confundida como uma mera transcrição, pois Saramago consegue criar um objeto esteticamente original ao ressignificá-las e, assim, expressar uma visão particular de mundo que o seu estatuto de criador requer. Afinal, é por meio de outros textos que o texto da tradição é contestado e redimensionado.

\section{REFERÊNCIAS BIBLIOGRÁFICAS}

BENJAMIN, Walter. Experiência e pobreza. In: Magia e técnica, arte e política: ensaios sobre literatura e história da cultura. Trad: Sergio Paulo Rouanet. 7. ed. São Paulo: Brasiliense, 1994.

BENJAMIN, Walter. O narrador. Considerações sobre a obra de Nikolai Leskov. In: Magia e técnica, arte e política: ensaios sobre literatura e história da cultura. Trad: Sergio Paulo Rouanet. 7. ed. São Paulo: Brasiliense, 1994.

DUARTE, Helena Margarida Vaz. Alguns aspectos da literatura tradicional/oral/popular nos romance de José Saramago. In: Narrativas em Metamorfose: abordagens interdisciplinares. BLAYER, Irene Maria F; FAGUNDES, Francisco Cota (orgs.). Cuiabá: Cathedral Publicações, 2009.

GONÇALVES, Henriqueta Maria. Encontros e desencontros da literatura tradicional/oral/popular. In: Narrativas em Metamorfose: abordagens 
interdisciplinares. BLAYER, Irene Maria F; FAGUNDES, Francisco Cota (orgs.). Cuiabá: Cathedral Publicações, 2009.

PELEN, Jean-Noël. Memória da literatura oral. A dinâmica discursiva da literatura oral: reflexões sobre a noção de etnotexto. Trad. Maria T. Sampaio. In: Projeto História - Revista do Programa de Estudos Pós-Graduados em História e do Departamento de História (PUC-SP), v.22, pp. 49-77, 2001.

SARAMAGO, José. A viagem do elefante: conto. São Paulo: Companhia das Letras, 2008. 